Correction

\title{
Correction: Hammer, J., et al. Short-Term Forecasting of Surface Solar Irradiance Based on Meteosat-SEVIRI Data Using a Nighttime Cloud Index. Remote Sens. 2015, 7, 9070-9090
}

\author{
Annette Hammer *, Jan Kühnert, Kailash Weinreich and Elke Lorenz \\ Department of Physics, University of Oldenburg, \\ Carl-von-Ossietzky-Str. 9-11, 26129 Oldenburg, Germany; \\ E-Mails: jan.kuehnert@uni-oldenburg.de (J.K.); kailash.weinreich@posteo.de (K.W.); \\ elke.lorenz@uni-oldenburg.de (E.L.) \\ * Author to whom correspondence should be addressed; E-Mail: annette.hammer@ uni-oldenburg.de; \\ Tel.: +49-441-798-3545; Fax: +49-441-798-3326.
}

Academic Editor: Prasad Thenkabail

Received: 14 October 2015 / Accepted: 16 October 2015 / Published: 21 October 2015

Due to an oversight by the authors, the following correction is necessary in this publication [? ]. In the third line of Equation (6) the decimal number 1.661 must be replaced by 1.1661 on page 9077 :

$$
k^{*}=1.1661-1.7814 n+0.7250 n^{2} \quad \text { for } 0.8<n \leq 1.05
$$

We apologize for any inconvenience caused to readers.

\section{Conflicts of Interest}

The authors declare no conflict of interest.

\section{References}

1. Hammer, A.; Kühnert, J.; Weinreich, K.; Lorenz, E. Short-term forecasting of surface solar irradiance based on Meteosat-SEVIRI data using a nighttime cloud index. Remote Sens. 2015, 7, 9070-9090.

(C) 2015 by the authors; licensee MDPI, Basel, Switzerland. This article is an open access article distributed under the terms and conditions of the Creative Commons Attribution license (http://creativecommons.org/licenses/by/4.0/). 